\title{
O Quão Pequeno é o Investimento Público no Brasil? Evidências Preliminares a partir de Comparações Internacionais
}

\author{
Bráulio Santiago Cerqueira* \\ Manoel Carlos de Castro Pires*
}

RESUMO - O crescimento recente da carga tributária no Brasil tem levado economistas e formadores de opinião em geral à insatisfação. Tem sido comum no debate o argumento de que o Governo investe pouco apesar do elevado nível de carga tributária, o que explicaria (em parte) o fraco desempenho econômico no período recente. O objetivo deste artigo é iluminar o debate apresentando evidências a partir das bases de dados das Contas Nacionais brasileiras e dos países da OCDE. Os dados de carga tributária bruta e líquida são comparados com os investimentos do Governo. As evidências mostram que não existe relação empírica direta relevante entre as variáveis, ou seja, países com maiores níveis agregados de tributação não necessariamente contam com Governos que investem mais. Ademais, pode-se perceber que após a forte retração de 2003 os investimentos públicos no Brasil têm se aproximado dos níveis exibidos pelos países da OCDE.

\section{INTRODUÇÃO}

O recente crescimento da carga tributária bruta - de 30,4\% do PIB em 2000 para $32,3 \%$ em 2002 e 34,1\% em 2006, conforme o IBGE - tem levado muitos economistas e formadores de opinião a argumentarem que a política fiscal no Brasil tem sido responsável pelo baixo crescimento econômico por desestimular o aumento do investimento privado e ao mesmo tempo não elevar de forma significativa os investimentos públicos em infraestrutura. Em que pesem, de um lado, a aceleração do ritmo de crescimento no período recente ${ }^{1} \mathrm{e}$, de outro lado, os resultados de trabalhos contrários a esta linha de argumentação - tais como o de Dos Santos e Pires (2009) que conclui que a elevação da carga tributária não tem impedido o aumento dos investimentos privados -, ainda hoje a idéia de que a carga tributária brasileira atravanca o dinamismo tem obtido bastante penetração no debate econômico:

"As dimensões e características da carga tributária e as comparações internacionais dão uma exata dimensão das distorções tributárias reinantes no Brasil. Tal carga retarda e desacelera a economia brasileira". (Afonso, 2009 p. 53, grifo meu).

\footnotetext{
* Analista de Finanças e Controle do MF. As opiniões aqui expressas não representam as opiniões da instituição. ** Técnico de Pesquisa e Planejamento do IPEA. As opiniões aqui expressas não representam as opiniões da instituição.

${ }^{1}$ No quinquênio compreendido entre 1999 e 2003 o PIB cresceu em média 1,9\% a.a.; no período seguinte, 2004 a 2008, a taxa média de crescimento da economia mais do que dobrou chegando a 4,8\% a.a..
} 
Um segundo ponto de preocupação na literatura tem sido o baixo nível de investimento público no Brasil. A idéia de que, apesar da elevada carga tributária, os investimentos públicos são baixos e insuficientes para gerar a infraestrutura necessária ao crescimento sustentado do país, tem comparecido com freqüência na agenda econômica:

"A combinação da extravagante carga tributária/PIB com enorme ineficiência do setor público coloca, certamente, o Estado brasileiro entre os mais pesados do mundo, sendo um dos fatores mais importantes a retardar a aceleração do nosso desenvolvimento econômico". (Delfim Netto, 2009, p. 29-30, grifo meu).

O raciocínio assim prossegue:

\begin{abstract}
"Como não houve aumento sensível dos investimentos governamentais no período, ele [o governo] utilizou esses recursos em seus gastos de custeio ou os distribuiu em programas sociais, alguns certamente muito necessários, mas feitos à custa da redução dos investimentos em infraestrutura (que também foi "consumida" no período) comprometendo, assim, a produtividade da economia". (Delfim Netto, 2009, p. 33, grifo meu).
\end{abstract}

Em suma, o argumento, presente em parcela expressiva de trabalhos técnicos e também amplamente veiculado na mídia, é que a Carga Tributária Bruta no Brasil é extremamente elevada e gera efeitos negativos sobre o crescimento econômico reduzindo o investimento privado sem proporcionar aumento do investimento público. Segundo essa linha de raciocínio, o investimento público é muito baixo apesar da elevada carga tributária bruta o que compromete o produto potencial.

É importante observar, em primeiro lugar, que esse argumento, conhecido como crowding in, faz sentido quando se considera não o total de investimento público, mas o investimento específico em infraestrutura realizado pelo setor público, o qual compreende apenas um subconjunto do total investido pelas administrações públicas. Essa qualificação é importante porque é possível que o investimento público aumente em setores onde a interação positiva com o setor privado seja pequena ou ocorra em setores em que o setor privado já funciona de maneira satisfatória gerando o efeito contrário, conhecido na literatura como crowding out. Dessa forma, é importante qualificar a tese da superioridade "natural" dos gastos em investimento sobre as despesas correntes do governo: a inversão pública pode incidir mais ou menos positivamente sobre a dinâmica econômica a depender do seu direcionamento concreto. A experiência brasileira recente, a propósito, aponta para o reconhecimento da importância e do caráter diferenciado dos investimentos públicos em 
infraestrutura, como aponta a formatação do Programa de Aceleração do Crescimento (PAC) lançado em 2007.

Em segundo lugar, é importante ressaltar que o conceito mais útil para a discussão da relação entre tributação e investimento é o de "disponibilização de recursos para investimento" e não apenas o agregado definido pela carga tributária bruta. Isto porque, em primeiro lugar, normalmente parte expressiva da carga tributária bruta - especialmente em países onde esta supera 30\% do PIB - já está comprometida com transferências ao setor privado, ou seja, não se presta ao financiamento do gasto público. A experiência internacional, aliás, tende a apontar que justamente o aumento das transferências do setor público ao setor privado - consubstanciado na conformação do Welfare State nos países avançados nos anos 1950 e 1960, ou no aumento das despesas com juros sobre o PIB no Brasil dos 1990 - se associa à elevação da carga tributária bruta onde esta se verificou. Por isso, a relação entre tributação e gasto público em inversão tende a ser mais bem observada por meio dos conceitos de carga tributária líquida (que exclui da carga bruta as transferências de renda) e de carga tributária líquida com a exclusão do pagamento de juros. Por outro lado, deve-se atentar para o fato de que o setor público conta com várias formas de elevar os investimentos em infraestrutura não relacionadas diretamente ao tamanho da carga tributária, tais como os investimentos das empresas estatais que podem ser realizados com recursos próprios das empresas ou créditos junto a terceiros; no Brasil, ademais, onde um banco público (BNDES) responde pela maior parte da oferta de crédito de longo prazo, a influência indireta (ou seja, não relacionada à inversão pública) do setor público sobre o investimento privado tende a ser maior.

A partir destas qualificações iniciais às críticas ao aumento da carga tributária e ao que se considera baixo patamar de investimento público no Brasil, essa nota tem por objetivo contribuir para o debate ao, de forma preliminar, apresentar um valor de referência para o nível de investimento público no Brasil. Este valor será construído a partir da confrontação da relação investimento público / Carga Tributária Líquida no Brasil com a observada nos países da OCDE em dois momentos no tempo, 2003 e 2006. A próxima seção faz uma breve discussão sobre a construção da base de dados e os limites técnicos da análise. A seção 3 apresenta os resultados para os anos de 2003 e 2006, respectivamente anos de contenção fiscal e moderada expansão fiscal no Brasil. Em seguida, haja vista a não divulgação até o momento (fevereiro de 2010) pelo IBGE das informações por setor institucional relativas à 
formação bruta de capital fixo para 2007 e 2008, a nota apresenta estimativas preliminares dos investimentos públicos no Brasil para este biênio. Por último, seguem as conclusões.

\section{METODOLOGIA}

A dificuldade na comparação internacional de dados fiscais reside principalmente nas diferenças metodológicas existentes entre os sistemas nacionais de contabilidade pública. Tais diferenças existem por várias razões: (i) a definição do que consiste o setor público e como o mesmo funciona em cada país, (ii) o fato do país ser mais centralizado (como é o caso de países pequenos) ou possuir uma grande federação (o que tende a descentralizar o processo orçamentário), (iii) a interação público-privado, que define se o investimento vai ser realizado diretamente pelo setor público ou pelo setor privado por meio de instrumentos legais tais como concessões, parcerias público-privado ou mesmo por meio de financiamentos públicos e (iv) os expurgos contábeis que são feitos em alguns países, especialmente os produtores de petróleo.

$\mathrm{Na}$ tentativa de enfrentar essas várias dificuldades, essa Nota utilizará os dados das Contas Nacionais do Brasil e dos países que integram a OCDE. A comparação com a OCDE é justificada pela recente convergência da Carga Tributária Bruta brasileira em relação à média dos países avançados e pela disponibilidade de informações. Quanto à utilização do Sistema de Contas Nacionais, por mais diferentes que sejam os procedimentos de apuração e as variadas classificações contábeis existentes, o esforço de padronização subjacente à construção de tais Sistemas oferece talvez a melhor base de comparação possível para as estatísticas macro-fiscais.

Ainda que se superem as dificuldades inerentes às comparações internacionais, a relação entre tributação e investimento público, conforme discutido brevemente na introdução, não é direta e sua discussão impõe uma série de qualificações. Em primeiro lugar, é importante ter claro que é difícil definir um nível ótimo de investimento público para qualquer país, na medida em que o patamar de gasto público, seja corrente ou de capital, responde a um conjunto de variáveis sócio-econômico-políticas (tais como grau de diversificação produtiva, papel do Estado na economia, estágio de conflito entre classes sociais etc.) irredutível à análise custo-benefício. Em segundo lugar, como os investimentos públicos não necessariamente conduzem a maior produtividade (como é o caso da construção de um edifício luxuoso para um órgão público que tem grande poder de barganha) é possível que elevadas despesas com investimentos signifiquem simplesmente desperdício de recursos 
públicos. Em terceiro lugar, existem várias outras formas de viabilização dos investimentos que não dependem diretamente da execução do setor público como é o caso das inversões das empresas estatais e dos financiamentos a partir de recursos públicos (bancos públicos, por exemplo).

Seguindo esta linha de raciocínio e a idéia já apresentada na introdução de "disponibilização de recursos para investimento", é importante destacar que a Carga Tributária Bruta não constitui a variável mais adequada para se conjecturar algo a respeito do volume concreto de investimento público, pois grande parte dos tributos e contribuições já está comprometida com transferências ao setor privado, como os benefícios previdenciários ou o pagamento de juros (IPEA, 2009). Pelos motivos expostos, este trabalho, além de relacionar o investimento público à Carga Tributária Bruta, também apresentará os dados de Carga Tributária Líquida e Carga Líquida menos juros dos diferentes países da amostra.

Uma última observação metodológica relevante diz respeito aos problemas específicos das estatísticas de investimento público no Brasil oficialmente trabalhadas nas Contas Nacionais pelo IBGE. Gobetti (2006) mostra com propriedade que os investimentos públicos do Governo Federal tendem a ser superestimados por conta do procedimento de liquidação forçada adotado pelo IBGE. Isso significa que as Contas Nacionais brasileiras consideram o segundo estágio da despesa pública, a liquidação, como gasto efetivo, o que em geral não corresponde à realidade: na prática, ao longo do tempo os valores efetivamente pagos pela União têm sido inferior aos valores liquidados. Assim, é importante que o volume de investimento público brasileiro apresentado nas Contas Nacionais seja devidamente ajustado para refletir melhor o dispêndio efetivo governamental.

Feitas as devidas qualificações, podemos nos voltar para a construção da base de dados. Nos países da OCDE, a Carga Tributária Bruta (CTB) no sistema de contas nacionais é obtida pela soma²: (i) dos impostos sobre capital (código GD91R), (ii) das contribuições sociais (código GD611R), (iii) dos impostos sobre a renda e riqueza (código GD5R) e; (iv) dos impostos sobre produção e importação (código GD2R). A formação bruta de capital fixo das administrações públicas também é divulgada pelas contas nacionais (código GP5_K2P). Para se chegar a Carga Tributária Líquida (CTL), basta excluir da CTB o total das transferências de renda dado pela soma dos subsídios (GD3P) e dos benefícios sociais (GD62P). Quanto à Carga Tributária Disponível (CTL-j), exclui-se da CTL o gasto com juros do governo (GD41P). No Brasil, os dados de Carga Tributária Bruta, investimento da

${ }^{2}$ Ver http://stats.oecd.org/Index.aspx?DatasetCode=SNA_TABLE12. 
administração pública, subsídios e transferências foram compilados diretamente do IBGE; o Banco Central do Brasil, por sua vez, constitui a fonte primária para obtenção do montante de pagamento de juros. Como o Sistema de Contas Nacionais divulgado pelo IBGE para o ano de 2007 não traz informações a respeito dos setores institucionais, a comparação internacional se estenderá somente até 2006. Estimativas próprias do investimento público no Brasil serão apresentadas para 2007 e 2008 em tópico específico. A comparação internacional se circunscreverá aos anos de 2003 e 2006. Tal comparação é particularmente útil porque o ano de 2003 no Brasil representou um ano de forte ajuste na política fiscal, em especial, dos investimentos públicos, e o ano de 2006, por sua vez, já apontava para a retomada dos investimentos públicos intensificada no período recente pelo PAC.

\section{RESULTADOS}

A Figura 1 apresenta, para o Brasil e os países da OCDE, a relação entre a CTB e os investimentos públicos para os anos de 2003 e 2006. Pode-se notar uma relação negativa entre as variáveis, ou seja, não parece haver evidências de que cargas tributárias mais elevadas estejam associadas a maiores montantes de investimento público. A Figura 2 ajuda a lançar luz sobre a questão mostrando, nos anos selecionados, inexistência de relação inversa (ou mesmo direta) clara entre a CTL e os investimentos públicos. Das informações depreende-se que, em 2003 e 2006, a relação negativa observada entre a CTB e os investimentos públicos se explica pelas transferências de renda e subsídios ao setor privado promovidas pelos diversos países.

É importante ponderar, contudo, que essas evidências não parecem muito fortes dado que a reta de ajuste linear é construída a partir da elevada variabilidade dos dados. Não obstante, deve-se observar que o Brasil situava-se bastante abaixo da reta das duas figuras para o ano de 2003, mas que em 2006 esta distância já havia diminuído. De todo o modo, em ambos os exercícios, para o volume de investimento público brasileiro atingir o valor de referência em relação ao nível de CTB ou CTL - valor este dado por aproximações lineares obtidas a partir de amostra dos países da OCDE - deveria situar-se próximo de 3\% do PIB. 
FIGURA 1 - CORRELAÇÃO ENTRE CTB E INVESTIMENTO PÚBLICO
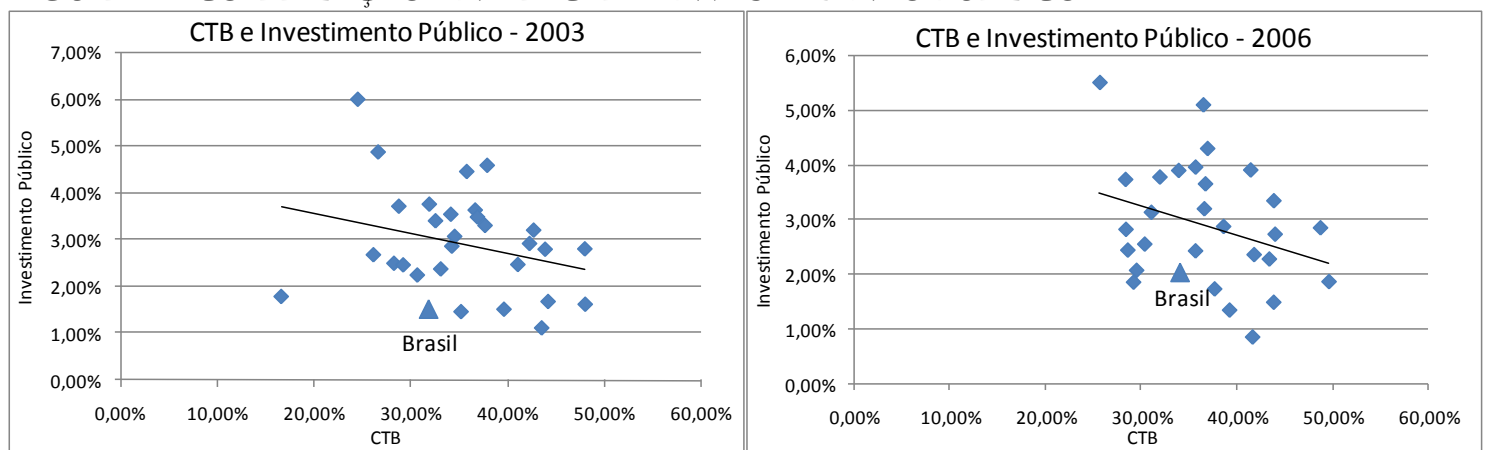

FONTE: OCDE e IBGE.
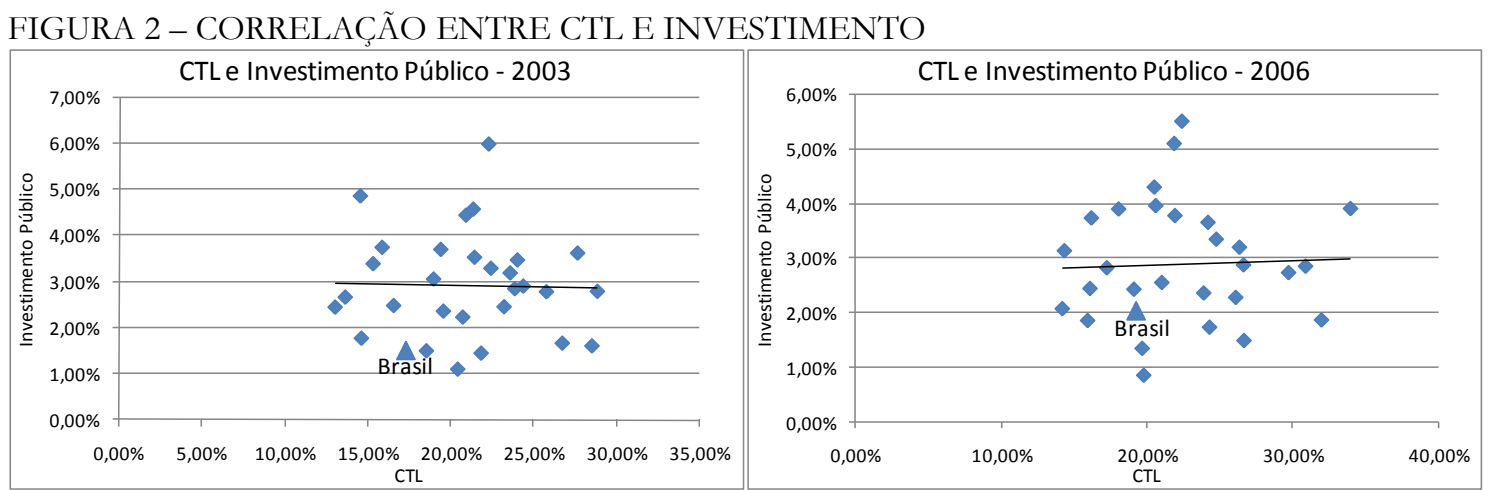

FONTE: OCDE e IBGE.

A Figura 3 apresenta a correlação entre a CTL sem o pagamento de juros e os investimentos públicos, nesse caso, levemente positiva. Novamente com a elevada dispersão dos dados essa reta de ajuste tem pouco significado. No entanto, assim como nas aproximações anteriores, pode-se dizer que no ano de 2003 o Brasil ficou muito aquém dos níveis de investimento público dos países da OCDE e que em 2006 o padrão brasileiro já se situava mais próximo do padrão da OCDE.

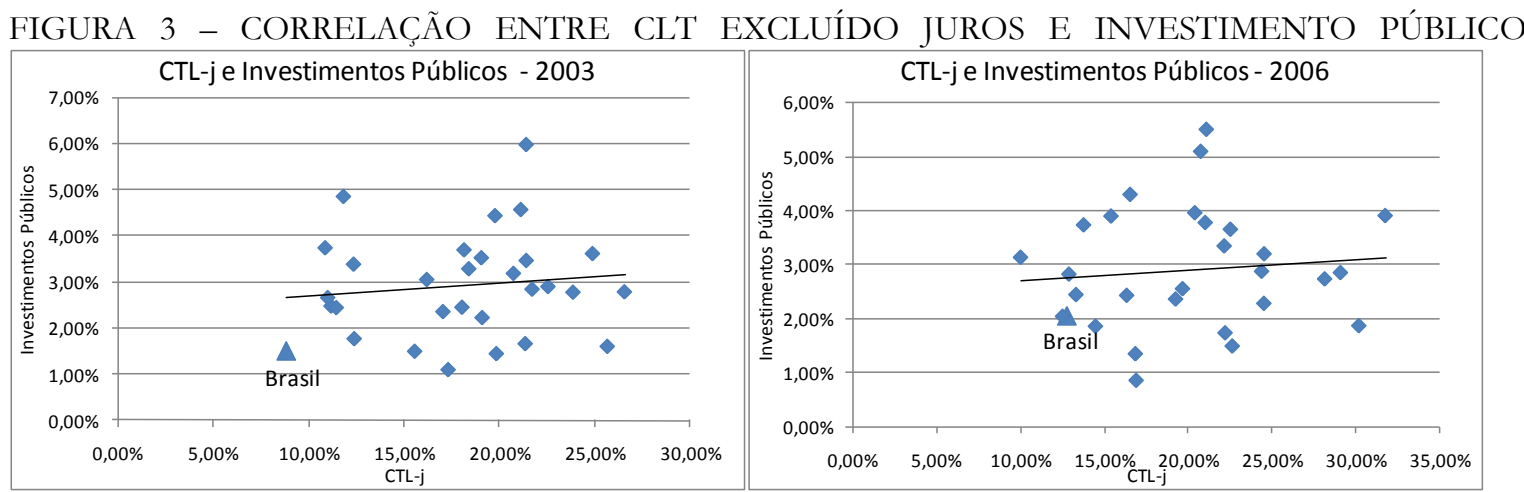

FONTE: OCDE e IBGE.

Seguem das Figuras 1-3 dois tipos de conclusões. A primeira é que não há, para os países da amostra, relação claramente definida entre os níveis de tributação e o volume de investimentos públicos realizados. A segunda é que, na comparação com a OCDE, o 
investimento público brasileiro situou-se em patamar muito baixo em 2003, mas em 2006 já se aproximava de um padrão internacional mínimo.

No que se refere à fraca relação entre níveis de tributação e investimento é importante ressaltar a já comentada forma de interação entre o setor público e privado, pois em muitos países existem formas indiretas de estímulo público ao investimento relacionado à importância do setor produtivo estatal na economia, ao peso dos bancos públicos nos esquemas de financiamento de longo prazo, às concessões e parcerias público-privadas etc. $\mathrm{O}$ baixo nível de investimento público observado em 2003 no Brasil, por sua vez, parece ter sido fruto da opção de política econômica pela intensificação do aperto fiscal e consequente redução no âmbito federal dos investimentos, de 0,8\% do PIB em 2002 para 0,3\% do PIB em 2003.

Uma possível conclusão a ser extraída dos exercícios é que a experiência recente dos países da OCDE indica que o nível de tributação brasileira (bruta, líquida ou disponível) sugere um patamar de referência para o investimento público ao redor de 3\% do PIB, na prática um montante próximo da média dos países envolvidos na análise.

\section{ESTIMATIVAS DOS INVESTIMENTOS PÚBLICOS PARA OS ANOS DE 2007 e 2008}

Tendo chegado a um valor de referência para o investimento público brasileiro em torno de 3\% do PIB, com todas as ressalvas já feitas, há que se perguntar como o mesmo evoluiu nos anos de 2007 e 2008. Dada a defasagem das Contas Nacionais brasileiras, esta seção fará uma breve discussão dos dados com o objetivo de apresentar estimativas preliminares para esses anos.

Como já registrado, os dados contábeis tendem apresentar diferenças significativas em relação aos dados das Contas Nacionais. Isso pode ser observado ao se contrastar a base de dados "Consolidação das Contas Públicas" elaborada pela Secretaria do Tesouro Nacional (STN) com os dados de investimento público divulgados pelo IBGE. A Tabela 1 apresenta as diferenças. Em todos os anos a diferença entre o investimento público agregado calculado pela STN e pelo IBGE se situa acima de 10\%. Uma possível explicação para esta discrepância reside, em grande medida, nas informações municipais, pois enquanto a STN utiliza o registro contábil de, praticamente, todos os municípios que fornecem as informações, o IBGE se baseia em uma pesquisa própria. Se utilizarmos o erro médio -14,8\% (IBGE $=-14,8 \%$ STN) no período de 2003 a 2006 para extrapolarmos os anos de 2007 e 2008, chega-se aos valores

40 
de $\mathrm{R}$ \$ 62,1 bilhões para 2007 e $\mathrm{R} \mathbf{7 9 , 9}$ bilhões para 2008, o que daria 2,34\% do PIB para 2007 e $\mathbf{2 , 6 6 \%}$ do PIB para 2008, um valor mais próximo da referência internacional obtida na seção anterior.

TABELA 1 - EVOLUÇÃO DO INVESTIMENTO PÚBLICO - STN x IBGE (R\$ milhões)

\begin{tabular}{l|r|r|r|r|r|r}
\hline & \multicolumn{1}{c}{$\mathbf{2 0 0 3}$} & \multicolumn{1}{c}{$\mathbf{2 0 0 4}$} & \multicolumn{1}{c}{$\mathbf{2 0 0 5}$} & \multicolumn{1}{c}{$\mathbf{2 0 0 6}$} & \multicolumn{1}{c}{$\mathbf{2 0 0 7}$} & $\mathbf{2 0 0 8}$ \\
\hline Investimentos Públicos IBGE & 25.604 & 33.405 & 37.490 & 48.245 & n.d & n.d \\
Investimentos Públicos STN & 29.674 & 37.913 & 45.396 & 57.259 & 72.874 & 93.703 \\
Diferença IBGE - STN (\%) & $-13,72 \%$ & $-11,89 \%$ & $-17,42 \%$ & $-15,74 \%$ & n.d. & n.d \\
Série IBGE estimada p/ 2007 e & & & & & & $\mathbf{7 9 . 9 3 7}$ \\
2008 & 25.604 & 33.405 & 37.490 & 48.245 & $\mathbf{6 2 . 1 6 8}$ & $\mathbf{2 , 6 6 \%}$ \\
Inv. Púb./PIB (\%) & $1,51 \%$ & $1,72 \%$ & $1,75 \%$ & $2,04 \%$ & $\mathbf{2 , 3 4 \%}$ & $\mathbf{2 , 6} \%$ \\
\hline
\end{tabular}

FONTE: STN E IBGE.

Uma estimativa alternativa pode ser obtida a partir de dados primários da União e dos Estados. A Tabela 2 apresenta a comparação dos dados da União, extraídos do SIAFI, e dos Estados, obtidos a partir da "Execução Orçamentária dos Estados" divulgada pela STN, com os dados já apresentados do IBGE. O primeiro ponto a se notar é que os erros nesse caso são muito maiores - o que não chega a surpreender haja vista a desconsideração dos municípios - e variam muito ano a ano, o que tende a dar menor precisão à estimativa. De todo modo, aplicando o erro médio de $34 \%$ aos registros contábeis, obtém-se valores estimados para o investimento público brasileiro de $\mathrm{R} \$ \mathbf{6 6 , 4}$ bilhões em 2007 e $\mathrm{R} \$ \mathbf{8 1 , 4}$ bilhões em 2008, o que, como proporção do PIB representa $2,49 \%$ e $\mathbf{2 , 7 1} \%$ respectivamente. Isto sugere como as estimativas da tabela 1 , que o nível de investimento público brasileiro vem se aproximando do valor de referência dado pelos países da OCDE.

TABELA 2 - EVOLUÇÃO DO INVESTIMENTO PÚBLICO - UNIÃO E ESTADOS x IBGE (R\$ milhões)

\begin{tabular}{l|r|r|r|r|r|r}
\hline & \multicolumn{1}{c|}{$\mathbf{2 0 0 3}$} & \multicolumn{1}{c|}{$\mathbf{2 0 0 4}$} & $\mathbf{2 0 0 5}$ & \multicolumn{1}{c}{$\mathbf{2 0 0 6}$} & \multicolumn{1}{c}{$\mathbf{2 0 0 7}$} & $\mathbf{2 0 0 8}$ \\
\hline Investimentos Públicos Estados & 10.392 & 12.234 & 15.812 & 18.602 & 15.503 & 24.550 \\
Investimentos Públicos União & 6.457 & 10.866 & 17.322 & 19.607 & 34.027 & 36.211 \\
União + Estados & 16.848 & 23.100 & 33.134 & 38.209 & 49.531 & 60.761 \\
Investimentos Públicos IBGE & 25.604 & 33.405 & 37.490 & 48.245 & n.d & n.d \\
Diferença IBGE - União e Estados (\%) & $51,97 \%$ & $44,61 \%$ & $13,15 \%$ & $26,27 \%$ & n.d & n.d \\
Série IBGE estimada p/ 2007 e 2008 & 25.604 & 33.405 & 37.490 & 48.245 & $\mathbf{6 6 . 3 6 9}$ & $\mathbf{8 1 . 4 1 7}$ \\
Inv. Púb./PIB (\%) & $1,51 \%$ & $1,72 \%$ & $1,75 \%$ & $2,04 \%$ & $\mathbf{2 , 4 9 \%}$ & $\mathbf{2 , 7 1 \%}$ \\
\hline
\end{tabular}

FONTE: Execução Orçamentária dos Estados e SIAFI.

Ainda sobre o investimento público no Brasil é importante destacar a questão da liquidação forçada, discutida brevemente na seção metodológica, que distorce as estatísticas públicas e das Contas Nacionais tendendo a inflá-las. Tais problemas nas rotinas contábeis, bastante conhecidos nas estatísticas da União, são de difícil identificação nas demais esferas de governo, o que torna mais incerta a determinação do viés. Na simulação abaixo somente o viés da União será tratado. 
Com efeito, a Tabela 3, como a Tabela 1, compara os investimentos públicos da STN com os valores obtidos das Contas Nacionais, mas desta vez procura ajustar o montante dos investimentos liquidados pela União pelo investimento efetivamente pago. Aplicando o erro médio no período de $-7,8 \%$, conclui-se que em 2007 os investimentos podem ter chegado a $\mathrm{R} \$ 53,9$ bilhões ou $\mathbf{2 , 0 2} \%$ do PIB e em 2008 podem ter totalizado $\mathbf{R}$ 77,8 bilhões ou $2,59 \%$ do PIB.

TABELA 3 - EVOLUÇÃO DO INVESTIMENTO PÚBLICO - IBGE COM AJUSTE PARA A UNIÃO (R\$ milhões)

\begin{tabular}{|c|c|c|c|c|c|c|}
\hline & 2003 & 2004 & 2005 & 2006 & 2007 & 2008 \\
\hline Investimentos Públicos IBGE & 25.604 & 33.405 & 37.490 & 48.245 & n.d & n.d \\
\hline Investimentos Públicos STN & 29.674 & 37.913 & 45.396 & 57.259 & 72.874 & 93.703 \\
\hline União Liquidado & 6.456 & 10.866 & 17.322 & 19.606 & 34.027 & 36.210 \\
\hline União Pago & 6.842 & 7.228 & 10.995 & 15.734 & 19.565 & 26.882 \\
\hline Investimentos Públicos STN com ajuste & 30.060 & 34.275 & 39.069 & 53.387 & 58.412 & 84.375 \\
\hline Diferença IBGE - STN ajustada (\%) & $-14,82 \%$ & $-2,54 \%$ & $-4,04 \%$ & $-9,63 \%$ & n.d & n.d \\
\hline Série IGBE ajustada & 27.728 & 31.615 & 36.038 & 49.245 & 53.880 & 77.828 \\
\hline Inv. Púb./PIB & $1,63 \%$ & $1,63 \%$ & $1,68 \%$ & $2,08 \%$ & $2,02 \%$ & $2,59 \%$ \\
\hline
\end{tabular}

FONTE: STN e IBGE.

\section{CONCLUSÕES}

Essa Nota teve por objetivo discutir a relação entre o investimento público e a tributação com base na experiência internacional e trazer elementos para possivelmente iluminar aspectos do debate no Brasil. O crescimento recente da carga tributária no país e as carências de infraestrutura acumuladas nas últimas décadas têm levado à insatisfação de vários economistas e formadores de opinião que argumentam que a carga tributária brasileira seria insuportavelmente elevada e os investimentos públicos baixos e insuficientes para gerar o crescimento econômico que o país precisa. Assim, a política fiscal seria extremamente ineficiente ao conjugar, do lado da receita, elevada carga e, do lado da despesa, baixo gasto em investimento.

A evidência obtida de países da OCDE indica que, em termos gerais, Cargas Tributárias Brutas maiores não necessariamente se relacionam a níveis mais elevados de investimento público. Em verdade, ajustes lineares simples dos dados para 2003 e 2006 produziram correlação negativa entre tributação bruta (CTB) e inversão pública. Essa correlação negativa torna-se nula quando os dados de investimento são comparados com a carga tributária líquida (CTL). Isso sugere que, na prática, países têm elevada carga tributária não para investir, mas para transferir renda. Quando os dados de investimento são comparados com a carga tributária líquida excluindo o pagamento de juros (CTL-j), uma pequena relação positiva é observada. Intuitivamente isso não deve surpreender afinal esta 
última medida de tributação se aproxima mais da disponibilidade efetiva de recursos do governo para o gasto em consumo e investimento.

Ressalvando os limites inerentes a qualquer comparação internacional e a dispersão relativamente grande dos dados da OCDE, o que torna as correlações obtidas apenas indicativas, o exercício proposto sugere um nível de investimento público ao redor de 3\% do PIB para o Brasil, patamar esse compatível com a "carga tributária disponível” do país. Diante disso, deve-se reconhecer que o Brasil vem convergindo para esse valor gradativamente. De 2003 para 2006 o investimento público subiu de 1,51\% do PIB para 2,04\% do PIB. Estimativas preliminares apontam que esse valor em 2008 se aproximou de 2,7\% do PIB, uma cifra não muito distante do valor de referência sugerido pela experiência recente da OCDE.

Por fim, lembre-se de que a teoria econômica, seja ela de corte ortodoxo ou heterodoxo, não estabelece níveis ótimos de tributação agregada e de investimento público aplicáveis a todas as economias a qualquer tempo. Daí a relevância para o tema, apesar de todas as limitações, de estudos comparativos internacionais. Esta Nota, ao cotejar Brasil e países da OCDE, relativiza a tese do tamanho "excessivo" da carga tributária brasileira, especialmente da "Carga Tributária Disponível” (bem abaixo da média da amostra, conforme o anexo estatístico - 8,9\% no Brasil contra 18,3\% do PIB na OCDE em 2003, e 12,5\% no Brasil contra 20,2\% do PIB na OCDE em 2006), e qualifica melhor a evolução recente do investimento da administração pública, de um baixo nível em 2003 para um patamar mais próximo da referência internacional em 2008.

\section{REFERÊNCIAS}

AFONSO, J. R. R.. (RE)Desenho Tributário. In: PISCITELLI, R.B., ELLERY Jr, R. e COSTA, T.. Reforma Tributária: A Costura de um Grande Acordo Nacional. Editora Atlas, 2009.

DELFim NeTTTO, A.. A Agenda Fiscal. In: GIAMBIAgI, F. e BARROS, O.. Brasil: Pós Crise. Editora Campus, 2009.

DOS SANTOS, C. H. e PIRES, M. C. C.. Qual a Sensibilidade dos Investimentos Privados a Aumentos na Carga Tributária Brasileira? Uma Investigação Econométrica. Revista de Economia Política, vol. 29, nº 3, pp. 213-231, 2009.

GOBETTI, S.. Estimativa dos Investimentos Públicos: um novo modelo de análise da execução orçamentária aplicado às contas nacionais. 51 f. Monografia ao XI Prêmio do Tesouro Nacional, ESAF, 2006.

IPEA. Carga Tributária Líquida e Efetiva Capacidade de Gasto Público no Brasil. Comunicados da Presidência, nº 23, 2009. 
TABELAS 4 E 5 - ANEXO ESTATÍSTICO

\begin{tabular}{l|c|c|c|c}
\hline \multicolumn{5}{c}{2 2003 } \\
\hline & CTB & CTL & CTL-j & INV. PÚBLICO \\
\hline Austrália & $30,68 \%$ & $21,33 \%$ & $19,08 \%$ & $2,23 \%$ \\
Áustria & $43,53 \%$ & $20,55 \%$ & $17,29 \%$ & $1,10 \%$ \\
Bélgica & $44,19 \%$ & $27,32 \%$ & $21,35 \%$ & $1,66 \%$ \\
Canadá & $28,27 \%$ & $17,11 \%$ & $11,14 \%$ & $2,48 \%$ \\
República Tcheca & $35,79 \%$ & $22,29 \%$ & $19,76 \%$ & $4,45 \%$ \\
Dinamarca & $48,03 \%$ & $29,84 \%$ & $25,66 \%$ & $1,61 \%$ \\
Finlândia & $43,89 \%$ & $25,48 \%$ & $23,86 \%$ & $2,78 \%$ \\
França & $42,70 \%$ & $24,06 \%$ & $20,73 \%$ & $3,19 \%$ \\
Alemanha & $39,64 \%$ & $18,13 \%$ & $15,54 \%$ & $1,50 \%$ \\
Grécia & $31,92 \%$ & $15,24 \%$ & $10,83 \%$ & $3,75 \%$ \\
Hungria & $37,68 \%$ & $21,91 \%$ & $18,38 \%$ & $3,29 \%$ \\
Islândia & $36,66 \%$ & $29,19 \%$ & $24,88 \%$ & $3,62 \%$ \\
Irlanda & $28,77 \%$ & $20,40 \%$ & $18,13 \%$ & $3,70 \%$ \\
Itália & $41,07 \%$ & $22,46 \%$ & $18,02 \%$ & $2,46 \%$ \\
Japão & $26,64 \%$ & $14,02 \%$ & $11,79 \%$ & $4,87 \%$ \\
Coréia & $24,53 \%$ & $21,34 \%$ & $21,40 \%$ & $5,99 \%$ \\
Luxemburgo & $37,90 \%$ & $20,79 \%$ & $21,11 \%$ & $4,58 \%$ \\
México & $16,62 \%$ & $13,99 \%$ & $12,36 \%$ & $1,77 \%$ \\
Holanda & $36,90 \%$ & $24,26 \%$ & $21,40 \%$ & $3,47 \%$ \\
Nova Zelândia & $34,25 \%$ & $24,39 \%$ & $21,71 \%$ & $2,85 \%$ \\
Noruega & $42,27 \%$ & $26,48 \%$ & $22,54 \%$ & $2,91 \%$ \\
Polônia & $32,56 \%$ & $14,94 \%$ & $12,32 \%$ & $3,39 \%$ \\
Portugal & $34,54 \%$ & $18,03 \%$ & $16,17 \%$ & $3,06 \%$ \\
República Slovakia & $33,10 \%$ & $17,44 \%$ & $17,02 \%$ & $2,36 \%$ \\
Espanha & $34,15 \%$ & $21,92 \%$ & $19,04 \%$ & $2,53 \%$ \\
Suécia & $47,99 \%$ & $29,57 \%$ & $26,56 \%$ & $2,45 \%$ \\
Suíça & $29,22 \%$ & $12,80 \%$ & $11,41 \%$ & $1,45 \%$ \\
Reino Unido & $35,20 \%$ & $22,50 \%$ & $19,83 \%$ & \\
USA & $26,15 \%$ & $13,96 \%$ & $10,96 \%$ & $8,67 \%$ \\
Brasil & $31,90 \%$ & $17,32 \%$ & $8,78 \%$ & \\
\hline FONT $\%$ & \\
\hline
\end{tabular}

FONTE: OCDE, IBGE e BCB.

\begin{tabular}{l|c|c|c|r}
\hline \multicolumn{5}{c}{$\mathbf{2 0 0 6}$} \\
\hline & CTB & CTL & CTL-j & INV. PÚBLICO \\
\hline Austrália & $30,32 \%$ & $21,04 \%$ & $19,70 \%$ & $2,55 \%$ \\
Áustria & $41,61 \%$ & $19,80 \%$ & $16,93 \%$ & $0,85 \%$ \\
Bélgica & $43,82 \%$ & $26,68 \%$ & $22,68 \%$ & $1,49 \%$ \\
Canadá & $28,36 \%$ & $17,27 \%$ & $12,91 \%$ & $2,82 \%$ \\
Rep. Tcheca & $36,47 \%$ & $21,89 \%$ & $20,79 \%$ & $5,09 \%$ \\
Dinamarca & $49,61 \%$ & $31,99 \%$ & $30,24 \%$ & $1,86 \%$ \\
Finlândia & $43,36 \%$ & $26,11 \%$ & $24,57 \%$ & $2,28 \%$ \\
França & $43,84 \%$ & $24,78 \%$ & $22,19 \%$ & $3,34 \%$ \\
Alemanha & $39,20 \%$ & $19,70 \%$ & $16,88 \%$ & $1,34 \%$ \\
Grécia & $31,02 \%$ & $14,36 \%$ & $10,02 \%$ & $3,13 \%$ \\
Hungria & $36,91 \%$ & $20,53 \%$ & $16,57 \%$ & $4,29 \%$ \\
Islândia & $41,42 \%$ & $33,98 \%$ & $31,82 \%$ & $3,90 \%$ \\
Irlanda & $31,91 \%$ & $21,94 \%$ & $21,06 \%$ & $3,77 \%$
\end{tabular}

44 


\begin{tabular}{lllll}
\hline Itália & $41,77 \%$ & $23,92 \%$ & $19,29 \%$ & $2,36 \%$ \\
Japão & $28,32 \%$ & $16,22 \%$ & $13,79 \%$ & $3,73 \%$ \\
Coréia & $25,64 \%$ & $22,42 \%$ & $21,13 \%$ & $5,50 \%$ \\
Luxemburgo & $35,65 \%$ & $20,62 \%$ & $20,44 \%$ & $3,95 \%$ \\
México & & & & \\
Holanda & $38,58 \%$ & $26,64 \%$ & $24,43 \%$ & $2,87 \%$ \\
Nova Zelândia & $36,56 \%$ & $26,36 \%$ & $24,58 \%$ & $3,19 \%$ \\
Noruega & $43,97 \%$ & $29,73 \%$ & $28,20 \%$ & $2,73 \%$ \\
Polônia & $33,88 \%$ & $18,08 \%$ & $15,43 \%$ & $3,89 \%$ \\
Portugal & $35,64 \%$ & $19,13 \%$ & $16,36 \%$ & $2,42 \%$ \\
Rep. Slovakia & $29,16 \%$ & $15,96 \%$ & $14,50 \%$ & $1,85 \%$ \\
Espanha & $36,68 \%$ & $24,21 \%$ & $22,57 \%$ & $3,65 \%$ \\
Suécia & $48,72 \%$ & $30,90 \%$ & $29,15 \%$ & $2,85 \%$ \\
Suíça & $29,47 \%$ & $14,22 \%$ & $12,82 \%$ & $2,07 \%$ \\
Reino Unido & $37,64 \%$ & $24,32 \%$ & $22,25 \%$ & $1,73 \%$ \\
USA & $28,55 \%$ & $16,12 \%$ & $13,33 \%$ & $2,44 \%$ \\
Brasil & $34,12 \%$ & $19,31 \%$ & $12,53 \%$ & $2,04 \%$ \\
\hline
\end{tabular}

FONTE: OCDE, IBGE e BCB. 
